\title{
Fabrication of Unidirectional Coir Fiber Reinforced Nonwoven Melt-Blown Glass Fabric Composite by Compression Molding
}

\author{
Abul Fazal Mohammad Fahad Halim¹*, Roy Ajoy' ${ }^{1}$ Chakma Arpan² and Mohammad Zulfikur Hasan Khan ${ }^{3}$ \\ ${ }^{1}$ Textile Engineering, World University of Bangladesh, Bangladesh \\ ${ }^{2}$ Textile Engineering, Zhejiang Sci-Tech University, China
}

${ }^{3}$ Textile Engineering, Ahsanullah University of Science and Technology, Bangladesh

*Corresponding author: RAbul Fazal Mohammad Fahad Halim, Textile Engineering, World University of Bangladesh, Dhaka, Bangladesh.

\begin{abstract}
The unidirectional composites of Coir Fiber with nonwoven melt blown glass fabric (C-G) were fabricated using compression molding. The reinforcement fibers were chemically treated with $\mathrm{NaOH}$ and silane coupling agent and then parallel placed with each other to prepare the unidirectional preforms. The parallel fibers were placed onto the metallic frame and dried before molding. The C-G layers was placed in heated mold for consolidation to produce the unidirectional composite specimens. The heated mold was cooled by the cooling system of the compression machine. Consolidation process involved three stages. At first, under certain temperature, the solid fibrous matrix materials became softened and then the matrix in the liquid form soaked and infiltrated the reinforcing fibers and finally during cooling stage, the matrix turned into solid form to hold the fibers in a definite position. The molding time affected the mechanical properties of the unidirectional composite. The C-G composite were characterized in the term of mechanical properties, dynamic mechanical analysis, and Fourier transformed infrared spectroscopy. The optimum compression molding parameters was $\mathrm{NaOH}$ treated coir fiber at processing time 8 min having processing temperature $170^{\circ} \mathrm{C}$ for fabricating unidirectional composite.
\end{abstract}

\section{Introduction}

FRP usually referred to as fibre reinforced polymer composite is a quite new material in the various applications such as construction and building industry compared to concrete and steel [1]. Composites possess the desired and preferred properties by coalescing dissimilar constituents in a cautious and judicious way. Generally, they possess higher specific modulus and high specific strength enabling them as a valuable material in huge number of industrialized requests which requires such features [2]. Carbon fibres and glass fibres integrated in polyester resin are the traditional and conventional fibre reinforced composite materials. These composite materials have excellent mechanical properties, but these materials cause environmental pollution due to the nondegradability of fibres [3]. Natural fibre reinforced composites found to be an alternative solution to the ever-depleting petroleum sources thus they receive greater attention, attraction from research scientist and community. Manufacturer and scientists attracted towards natural fibre based composites due to its biodegradability, light in weight, nontoxic and relatively stronger and consider being virtuous products which can be used in construction industry, automotive industry and for furniture production [4]. Natural fibre composites have better formability, abundant, renewable, cost effective, possess tool wearing rates, thermal insulation properties, acoustic properties, sufficient energy requirements and safer towards health [5]. Many innumerable demerits such as hydrophilic in nature, poor fibre/matrix interfacial adhesion and poor thermal stability of natural fibres can be overcome by chemical treatment or compatibilizer which amended the adhesion between the fibre and matrix. Composite of polymers and Coir fibre possess the variances and incomparability in terms of their polarity structures [6]. Based on the origin natural fibres are categorized as animal based and plant based. Animal-based fibres are wool, silk, 
etc. and natural fibres based on plant includes sisal, coir, ramie, jute, bamboo, pineapple and many more [2]. Lignocellulosic fibres possess many compensations of being financially reasonable to manufacture such as lightweight, eco-friendly, harmless to health, high stiffness and specific strength which provides a probable substitute to the synthetic or artificial fibre $[7,8]$. The reinforcing capability of the fibres mainly influenced by various aspects such as polarity of the fibre, mechanical strength of the fibres, surface appearances, and existence of reactive centers [9]. Moreover, many of the natural fibres properties are governed by several factors such as climate, harvest, maturity, variety, decortications, retting degree, disintegration (steam explosion treatment, mechanical), fibre modification, technical and also textile processes (spinning and carding) [9]. In spite of these promising features shown by natural fibres certain major drawbacks are also underlined like water absorption, strength degradation, lack in thermal stability lowered impact properties $[10,11]$ but it has been found that these can be improved and overcome by hybridization with either natural or synthetic fibre. Bast fibres derived from natural fibres such as coir, hemp, flax, kenaf and jute have high specific strength, low density and are extremely concerned in several industrial applications [12]. Coir fibres are gratifying increasingly widespread throughout the world as a significant natural materials source contributing towards the development of eco-friendly assets for the automotive, sports industries, food packaging and furniture [13], textiles, paper pulp, and fibre boards-based industries [14]. Inferior thermal resistance is displayed by coir as compared to artificial or synthetic fibres such as (aramid, glass fibres) like all other natural fibres [1]. Coir is in an advantageous position when compared with other lignocellulosic fibre crops since it has a short plantation cycle, flexibility to environmental conditions and requires relatively lowered quantity of pesticides and herbicides [15]. Coir fibres receive much attention owing to its prospective probability as polymer reinforcements in the natural fibre composite industry. Researchers claimed that mechanical strength and thermal properties of coir composite are superior to other type of natural fibre polymer composites, thus regarded as a suitable applicant for high-performance natural fibre polymer composites [14]. The coir fibre as reinforcement materials are full-fledged noticeably from the past decade along with other products such as extruded plastic fencing, decking, and furniture padding [3]. Coir composites can eventually, supplement and substitute petroleum based composite materials in many of the known industrial applications, and thus proposing innovative environmental, agricultural, manufacturing and consumer profits formulation methods [16,17].

\section{Experimental}

\section{Materials and methods}

Materials: Coir fiber has been collected from Gazipur District (Bangladesh). After collection, the fibers were washed and dried in order to remove impurities like sand, leaves etc. Melt-blown nonwoven glass fiber fabric was collected from Shanghai Macklin Biochemical Co. Ltd.
Chemical modification of coir fiber: Coir fibers were soaked in a solution of $\mathrm{NaOH}$ and silane coupling agent $(7 \% \mathrm{NaOH}$ and $7 \%$ silane coupling, $7 \mathrm{~g} / 100 \mathrm{~mL}$ of water) for maximum $3 \mathrm{~h}$ at room temperature. After $3 \mathrm{~h}$, ramie fibers were rinsed in tap water with a drop of acetic acid until excess $\mathrm{NaOH}$ was washed way.

Composite fabrication: The melt-blown glass sheets were cut to the desired size $(12 \mathrm{~cm} \times 12 \mathrm{~cm})$ for composite manufacturing Coir fibers were cut into the length of $12 \mathrm{~cm}$. Two layers of unidirectional fibers were inserted between three sheets of preweighted glass sheets during the fabrication of composite. Fibers volume ratio was chosen to be 3:7. The fibers were embedded randomly in between glass sheets. By this way, a sandwich is formed which was then employed between two steel plates under a pressure of $5 \mathrm{MPa}$ for $8 \mathrm{~min}$ with keeping the temperature of $170^{\circ} \mathrm{C}$. The thickness of the resultant composites was kept $2 \mathrm{~mm}$. Testing specimens were prepared from the composite sheet by cutting with grinding machine carefully. Figure 1 shows the schematic fabrication layout of composite laminates (Table 1). Represents the sample specifications of different composites.

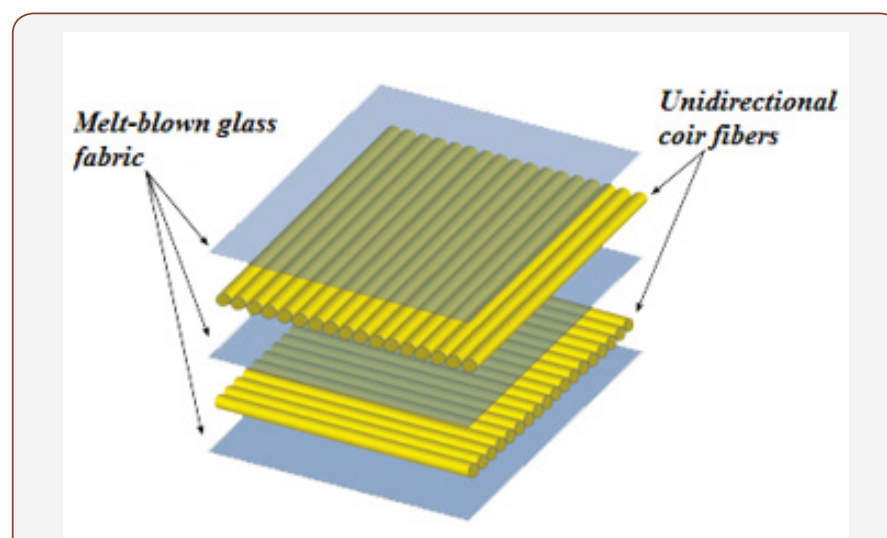

Figure 1: Schematic fabrication layout of composite laminates.

Table 1: Sample specifications.

\begin{tabular}{|c|c|c|c|c|c|}
\hline $\begin{array}{l}\text { SL } \\
\text { No }\end{array}$ & Symbol & Composite & $\begin{array}{l}\text { Process- } \\
\text { ing Time } \\
(\mathrm{min})\end{array}$ & $\begin{array}{c}\text { Processing } \\
\text { Temperature } \\
\left({ }^{\circ} \mathrm{C}\right)\end{array}$ & $\begin{array}{c}\text { Processing } \\
\text { Pressure } \\
\text { (MPa) }\end{array}$ \\
\hline \multirow[t]{3}{*}{1} & C1 & \multirow{3}{*}{$\begin{array}{l}\text { Alkali-treat- } \\
\text { ed coir+ } \\
\text { Nonwoven } \\
\text { glass sheet }\end{array}$} & 6 & \multirow{3}{*}{170} & \multirow{3}{*}{5} \\
\hline & $\mathrm{C} 2$ & & 8 & & \\
\hline & C3 & & 10 & & \\
\hline \multirow[t]{3}{*}{2} & $\mathrm{C} 4$ & \multirow{3}{*}{$\begin{array}{c}\text { Si- } \\
\text { lane-treated } \\
\text { coir + Non- } \\
\text { woven glass } \\
\text { sheet }\end{array}$} & 6 & \multirow{3}{*}{170} & \multirow{3}{*}{5} \\
\hline & $\mathrm{C} 5$ & & 8 & & \\
\hline & C6 & & 10 & & \\
\hline \multirow[t]{3}{*}{3} & C7 & \multirow{3}{*}{$\begin{array}{l}\text { Raw coir + } \\
\text { Nonwoven } \\
\text { glass sheet }\end{array}$} & 6 & \multirow{3}{*}{170} & \multirow{3}{*}{5} \\
\hline & $\mathrm{C} 8$ & & 8 & & \\
\hline & C9 & & 10 & & \\
\hline
\end{tabular}

\section{Mechanical Tests}

Tensile strength was investigated by following the DIN 53455 standard method using a Hounsfield S series Universal Testing Machine, model: H $50 \mathrm{KS}-0404$. The cross-head speed was set $10 \mathrm{~mm} / \mathrm{min}$ during testing and the gauge length was $20 \mathrm{~mm}$. The 
geometry of the test specimen was maintained $60 \mathrm{~mm} \times 15 \mathrm{~mm}$ $\times 2 \mathrm{~mm}$. The data was recorded at room temperature $\left(20^{\circ} \mathrm{C}\right)$ and constant relative humidity of $65 \%$.

\section{Dynamic mechanical analysis (DMA)}

The dynamic mechanical analysis test was performed in a tension mode on DMA METTLER TOLEDO (DMA star system, made in the USA). The size of the specimen was cut to a dimension of 15 $\mathrm{mm} \times 5 \mathrm{~mm} \times 3 \mathrm{~mm}$ and testing was performed in a temperature range of $30-200^{\circ} \mathrm{C}$ with a heating rate of $3 \mathrm{~m} / \mathrm{min}$.

\section{Surface analysis}

The Fourier transform infrared spectroscopy, FTIR (Perkin Elmer) analysis was used to evaluate the changes of surfaces happened to ramie fibers before and after treatments. Before testing, the prepared samples were mixed with Potassium Bromide
(KBr) powder. Then, the FTIR spectra were taken for all samples in a range of $500-4000 \mathrm{~cm}^{-1}$.

\section{Thermal analysis}

The Thermogravimetric Analysis (TGA4000) was taken to analyze the thermal degradation procedure of C-G composite within a temperature range of $30-800^{\circ} \mathrm{C}$. TGA characterization was carried out in a nitrogen gas media at a heating rate of $20^{\circ} \mathrm{C} \mathrm{min}^{-1}$, in a sealed vessel.

\section{Result and Discussion}

\section{Mechanical tests}

Figure 2 depicts the tensile strength C-G composite for different processing conditions. The tensile strengths of composite for sample C2, C5, C8 were 30.91, 29.21, and 23.22 MPa, respectively.

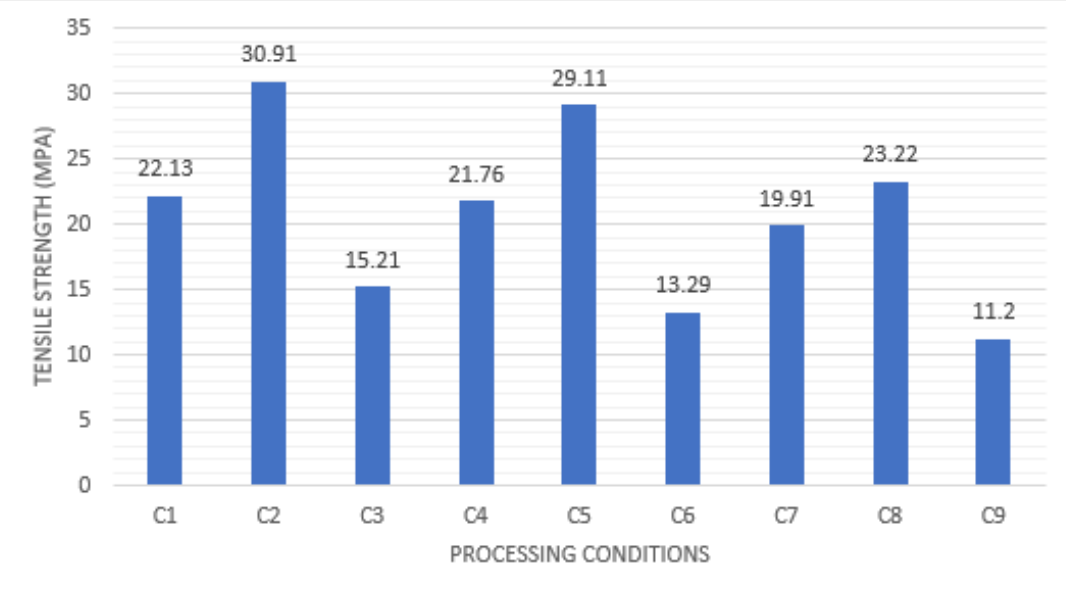

Figure 2: Tensile strength of C-G composites of different processing conditions.

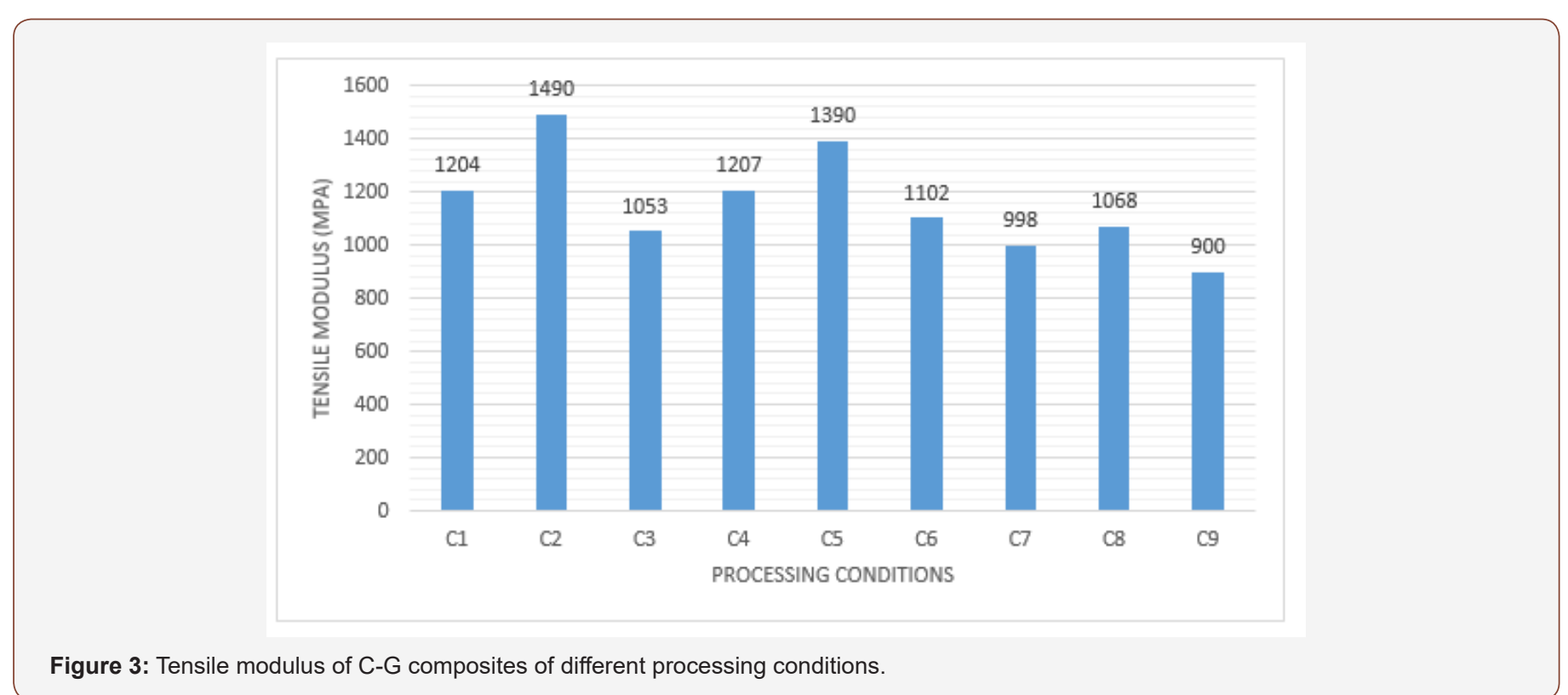

Suitable working parameters are quite essential to produce outstanding products with the required physical and chemical qualities wanted. In this case, the combined processing condition of
C2 is more significant. The tensile strength of composite materials is straightly depending on the strength and modulus of the reinforcing fibers, orientation and length of the fiber, fiber loading, 
as well as fiber-matrix interfacial adhesion. These variable factors can explain the circumstances that the mechanical properties obtained for C-G composite at higher processing temperature are lower. Other reason can be tensile strength variation of meltblown glass sheet as it melts and gets brittle at higher temperature. The effect of alkali, silane can be seen from the results of tensile strength. Whatever the processing condition, the modification of alkali or silane treatment has greatly improved the tensile strength of C-G composites. Figure 3 represents the tensile modulus of C-G composites of different processing conditions

\section{Dynamic mechanical analysis (DMA)}

DMA test results provide the effect of elevated temperature on the stiffness of coir fibers reinforced glass composite. Here, the information can be obtained in the form of storage modulus, loss modulus, and $\tan \delta$. The temperature dependency (dynamic mechanical properties) of C-G composites are presented in Figure 4.
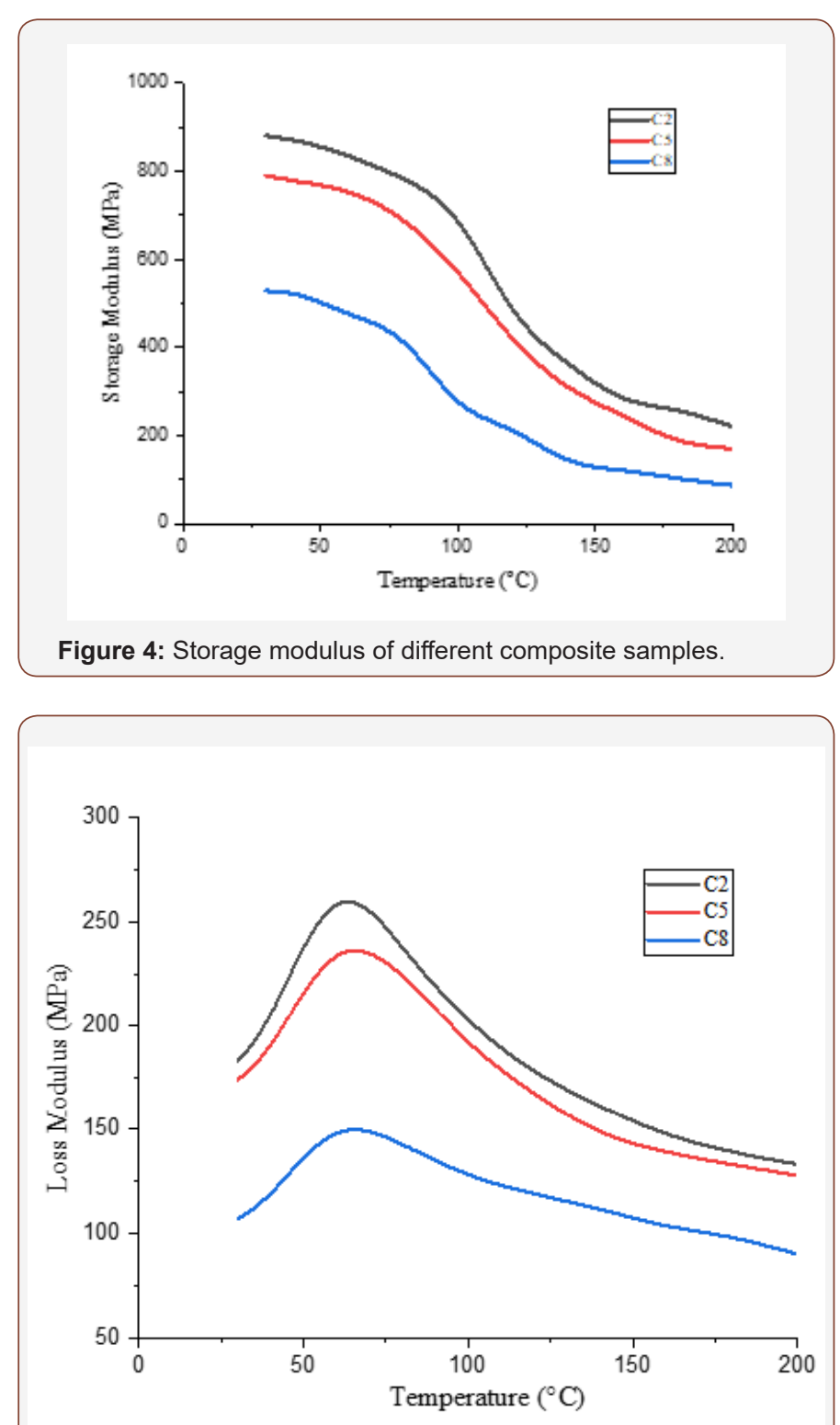

Figure 5: Tan delta of different composite samples.
It can be clearly seen that the dynamic mechanical properties of the samples nearly showed a similar pattern. The storage moduli of tested samples closely mean to define the load bearing capacity of $\mathrm{C}-\mathrm{G}$ composite. The storage modulus of $\mathrm{C} 2$ composite was higher than others. The higher value indicates the higher stiffness and load bearing capacity of coir fibers in the reinforcement system. Similar to the storage modulus, the loss modulus illustrates the maximum heat dissipation of C-G composite. The loss modulus of all samples showed a decrease with increasing temperature, and there was a significant fall in a region of $60-80^{\circ} \mathrm{C}$. As it can be seen in from Figure 5, the maximum heat dissipation occurs at a maximum temperature where loss modulus was highest, indicating the glass transition (Tg) of the material. The ratio of loss modulus to storage modulus could illustrate the mechanical loss factor $(\tan \delta$ ) of C-G composites.

From Figure 6, the impact resistances of C-G composites were significantly improved by reinforcement of coir fibers.

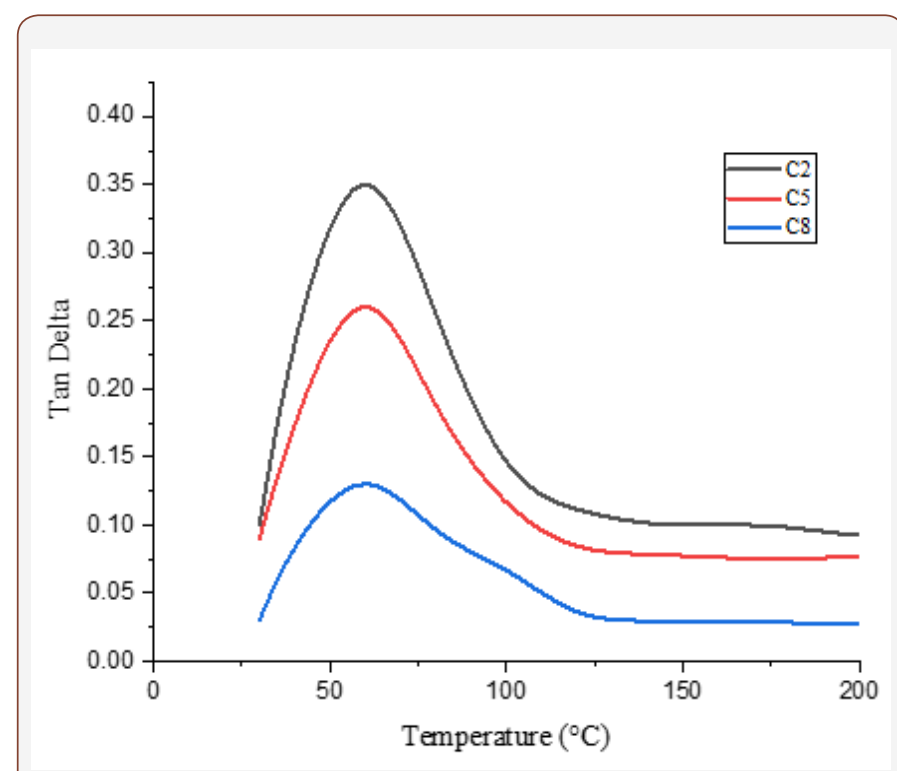

Figure 6: Tan delta of different composite samples.

\section{Surface analysis}

Figure 7 represents the FT-IR spectra of different composite samples. From the spectra study, it is evident that the absorption peaks of $3447 \mathrm{~cm}^{-1}$ for all samples were allocated to $\mathrm{OH}$ stretching of $\alpha$-cellulose [18,19]. Meanwhile, the absorption band at 2946 $\mathrm{cm}^{-1}$ were attributed to $\mathrm{CH}$ and $\mathrm{CH} 2$ stretching vibrations [19]. Furthermore, vibration peaks observed at $1734 \mathrm{~cm}^{-1}$ in the spectrum of the bast which denotes $\mathrm{C}=0$ stretching of methyl ester and carboxylic acid or the acetyl group in hemicelluloses was drastically decreased for C2 and C5 sample due to the successful removal of the pectin and hemicelluloses during their treatment with $\mathrm{NaOH}$ and silane [19]. On the other hand, the absorption band at $1636 \mathrm{~cm}^{-1}$ of the C8 was drastically decreased and shifted to $1629 \mathrm{~cm}^{-1}$ for $\mathrm{C} 2$ which is attributed to antisymmetric COOstretching which proves the efficiency of $\mathrm{NaOH}$ treatment method to remove lignin from the bast fibers [18]. Moreover, absorption 
peaks observed at $1375 \mathrm{~cm}^{-1}$, which denotes $\mathrm{CH}_{2}$ and $\mathrm{CH}$ symmetric bending mode, respectively [19]. Besides, absorption peaks in the fingerprint regions at $1164 \mathrm{~cm}^{-1}$ and $1058 \mathrm{~cm}^{-1}$ attributed to cellulose structure $[18,19]$. In addition, absorption peaks at $1311 \mathrm{~cm}^{-1}$ and $898 \mathrm{~cm}^{-1}$ were associated with $\mathrm{C}-\mathrm{H}$ scissoring and C-C bending $[20,21]$. And, the small peaks at $832 \mathrm{~cm}^{-1}$ ascribed to aromatic C-H out-of-plane vibration in the lignin was decreased in intensity after the degumming process [22]. Consequently, it very well may be reasoned that the absorption peaks of all the noncellulose substances, for instance, hemicellulose, pectin, lignin, and wax-like substances, were missing or radically decreased for C2 than that of $\mathrm{C} 5$ and $\mathrm{C} 8$.

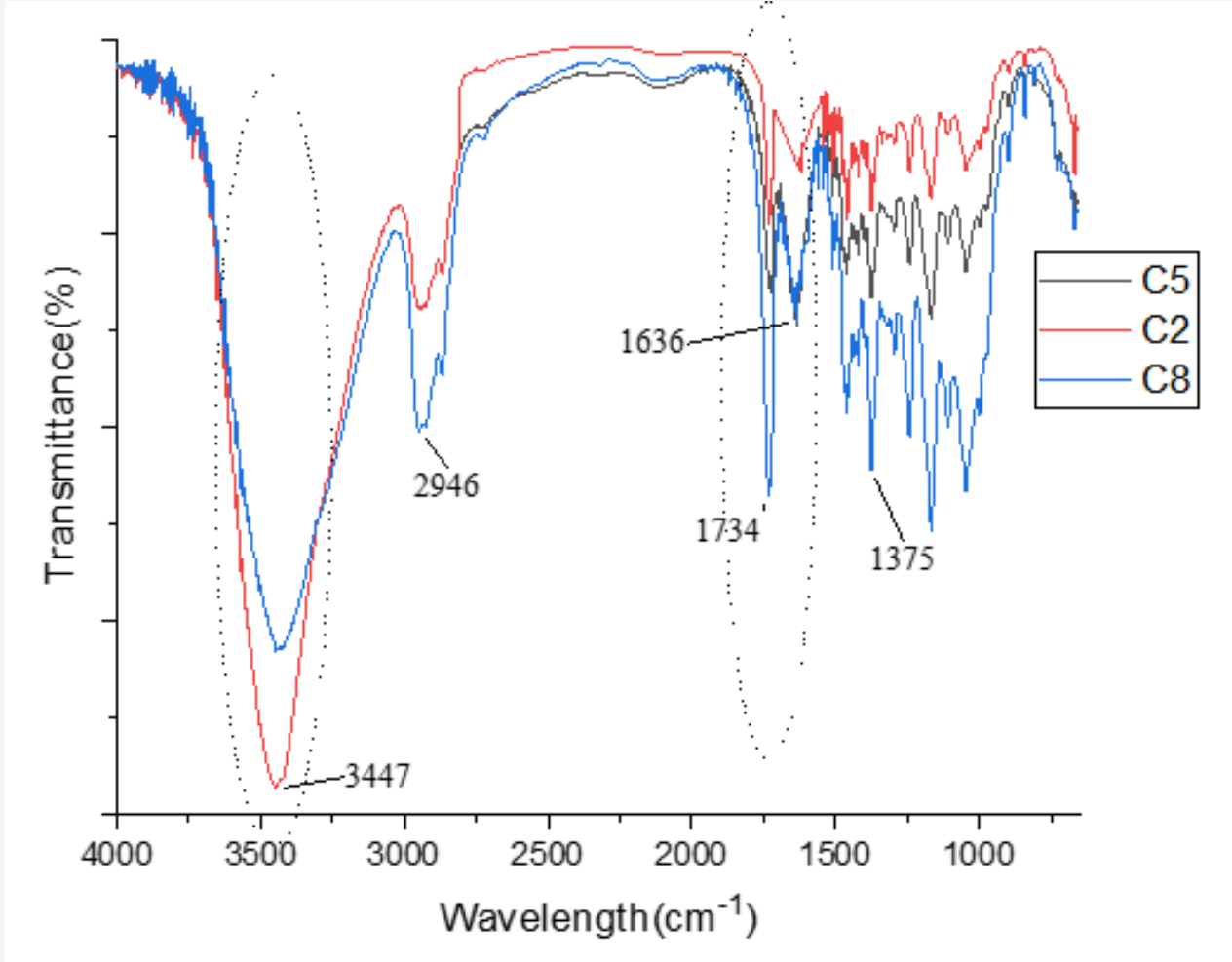

Figure 7: FT-IR spectra of composites.

\section{Thermal analysis}

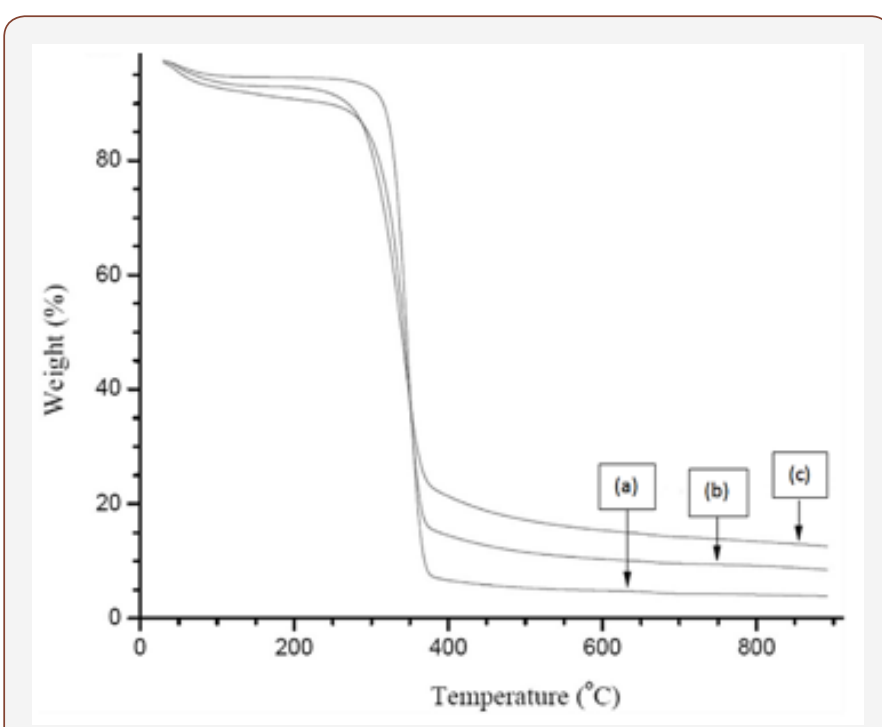

Figure 8: TGA curves of composites a) C5, b) C2, and c) C8.

Figure 8 shows the thermogravimetric analysis curves of $\mathrm{C} 5$, $\mathrm{C} 2$, and C8 composite samples. It is evident from the curves that all samples depict two stages of thermal degradation patterns. Initial weight loss due to evaporation of water and other volatile compounds within the samples takes place between the temperature range $60-150^{\circ} \mathrm{C}$. Cellulose decomposition for $\mathrm{C} 8, \mathrm{C} 2$, and $\mathrm{C} 5$ starts from $296.4^{\circ} \mathrm{C}, 313.9^{\circ} \mathrm{C}$, and $325.3^{\circ} \mathrm{C}$, respectively. The thermogravimetric analysis (TGA) results confirmed that the chemical treatment of coir fibers and addition of treated fibers to the nonwoven glass fabric increased the thermal resistance of the composite.

\section{Conclusion}

In this study, a composite containing coir and nonwoven melt blown glass fabric was manufactured by hot compression molding. Alkali treated modified coir fibers composite showed better mechanical properties with a significant improvement of surface compatibility over silane treated and untreated composites. Nine processing conditions were prepared to find the optimization properties of the composites. Accordingly, a suitable processing condition was selected as sample $\mathrm{C} 2$ with fibers volume ratio of 3:7, molding temperature of $170^{\circ} \mathrm{C}$, a molding pressure of $5 \mathrm{MPa}$ and 8 min of processing time, respectively.

\section{Acknowledgement}

None.

\section{Conflict of Interest}

No conflict of interest. 


\section{References}

1. Azwa ZN, Yousif BF (2013) Characteristics of kenaf fibre/epoxy composites subjected to thermal degradation. Polymer degradation and stability 98(12): 2752-2759.

2. Nunna S, Chandra PR, Shrivastava S, Jalan A (2012) A review on mechanical behavior of natural fiber-based hybrid composites. Journal of Reinforced Plastics and Composites 31(12): 759-769.

3. Thiruchitrambalam M, Alavudeen A, Athijayamani A, Venkateshwaran $\mathrm{N}$, Perumal AE (2009) Improving mechanical properties of banana/kenaf polyester hybrid composites using sodium laulryl sulfate treatment. Mater Phys Mech 8: 165-173.

4. Paukszta D, Borysiak S (2013) The Influence of Processing and the Polymorphism of Lignocellulosic Fillers on the Structure and Properties of Composite Materials-A Review. Materials 6: 2747-2767.

5. Davoodi MM, Sapuan SM, Ahmad D, Ali A, Khalina A, et al. (2010) Mechanical properties of hybrid kenaf/glass reinforced epoxy composite for passenger car bumper beam. Materials \& Design 31(10): 4927- 4932.

6. Rassiah K, Megat Ahmad MM (2013) A Review on Mechanical Properties of Bamboo Fiber Reinforced Polymer Composite. Australian journal of basic and applied sciences 7(8): 247-253.

7. Athijayamani A, Thiruchitrambalam M, Manikandan V, Pazhanivel B (2010) Mechanical properties of natural fibers reinforced polyester hybrid composite. International Journal of Plastics Technology14(1): 104-116

8. Kumar NM, Reddy GV, Naidu SV, Rani TS, Subha MC (2009) Mechanical Properties of Coir/Glass Fiber Phenolic Resin Based Composites. Journal of reinforced plastics and composites 28(21): 2605- 2613.

9. Kalia S, Kaith B, Kaur I (2009) Pretreatments of natural fibers and their application as reinforcing material in polymer composites-A review. Polymer Engineering \& Science 49(7): 1253-1272.

10. Adekunle K, Cho SW, Patzelt C, Blomfeldt T, Skrifvars M (2011) Impact and flexural properties of flax fabrics and Lyocell fiber-reinforced biobased thermoset. Journal of Reinforced Plastics and Composites 30(8): 685-697.

11. Alawar A, Hamed AM, Al-Kaabi K (2009) Characterization of treated date palm tree fiber as composite reinforcement. Composites Part B: Engineering 40(7): 601-606.
12. Zhu J, Zhu H, Njuguna J, Abhyankar H (2013) Recent Development of Flax Fibres and Their Reinforced Composites Based on Different Polymeric Matrices. Materials 6: 5171-5198.

13. Anuar H, Zuraida A (2011) Improvement in mechanical properties of reinforced thermoplastic elastomer composite with kenaf bast fibre. Composites Part B: Engineering 42(3): 462-465.

14. Nishino T, Hirao K, Kotera M, Nakamae K, Inagaki H (2003) Kenaf reinforced biodegradable composite. Composites science and technology 63(9): 1281-1286.

15. Wang J, Ramaswamy GN (2003) One-Step Processing and Bleaching of Mechanically Separated Kenaf Fibers: Effects on Physical and Chemical Properties. Textile Research Journal 73(4): 339-344.

16. Krishnaprasad R, Veena N, Maria HJ, Rajan R, Skrifvars M, et al. (2009) Mechanical and Thermal Properties of Bamboo Microfibril Reinforced Polyhydroxybutyrate Biocomposites. Journal of Polymers and the Environment 17: 109.

17. Han G, Lei Y, Wu Q Kojima Y, Suzuki S (2008) Bamboo-Fiber Filled High Density Polyethylene Composites: Effect of Coupling Treatment and Nanoclay. Journal of Polymers and the Environment 16(2): 123-130.

18. During JR, Craven S, Harris W (1981) Vibrational spectra and structure. Elsevier Amsterdam.

19. Silverstein RM, Webster FX (1998) Spectrometric identification of organic compounds $\left(6^{\text {th }}\right.$ edn), Wiley, New York, USA.

20. LX (2015) Study on quality evaluation method of rose and Apocynum Venetum in XinJiang based on infrared spectroscopy. Xinjiang University China.

21. John SJ, Donal EC (1989) Negativity and extremity biases in impression formation: A review of explanations.

22. Sun R, Lawther JM, Banks WB (1996) Effects of pretreatment temperature and alkali concentration on the composition of alkalisoluble lignins from wheat straw. Journal of Applied Polymer Science 62(9): 1473-1481. 